\title{
How do Tertiary Education Students Perceive Co-Curricular Activities under the New Education System?
}

\author{
Helen Wong ${ }^{1} \&$ Simon Leung ${ }^{1}$ \\ ${ }^{1}$ The Hong Kong Polytechnic University, Hong Kong Community College, Hong Kong \\ Correspondence: Helen Wong, The Hong Kong Polytechnic University, Hong Kong Community College, 9 Hoi \\ Ting Road, Kowloon, Hong Kong. Tel: 1-852-9157-3436. E-mail: cchelen@hkcc-polyu.edu.hk
}

Received: July 17, 2017

doi:10.5539/ies.v11n2p83
Accepted: September 1, 2017 Online Published: January 26, 2018

URL: https://doi.org/10.5539/ies.v11n2p83

\begin{abstract}
Co-curricular activities in general are believed to be useful for students' development, such as improvement in academic performance, higher retention rate, enhancement of social and competency skills, and assistance of youth development and employment. With the expansion of the education sector and the implementation of a new 3-3-4 education system in Hong Kong, the background and training of students is different from the past, so it is worthwhile investigating students' interest, understanding and perceptions about co-curricular activities nowadays in an Asian context. Comparison between the perceptions of sub-degree and degree students is discussed. Similarities and differences are found in both groups of students. Based on the findings, suggestions are made to education institutions in planning their resources on co-curricular activities.
\end{abstract}

Keywords: co-curricular activities, tertiary education, sub-degree, degree, students, perceptions

\section{Introduction}

The tertiary education sector in Hong Kong has undergone rapid growth in the past decade. The government has been making great effort to promote the development of tertiary education. Since the announcement of the government to support an initiative of giving $60 \%$ of our younger generation access to tertiary education in $2000 / 01$, both government-funded and self-financed degree and sub-degree places and programmes have expanded sharply. Together with the expansion, the new 3-3-4 Education System also started implementation in Hong Kong from 2012. The 3-3-4 education system is a new academic structure for senior secondary education and tertiary education in Hong Kong. "3-3-4" represents 3 years of junior secondary school, 3 years of senior secondary school, and 4 years of university. Compared to the old system, there is only one external public examination, namely the Hong Kong Diploma of Secondary Education (HKDSE), before tertiary studies, while students had to go through two external public examinations under the old system. Life-long learning and all-round development are the core spirits of the reform (Education Bureau, 2010).

To align with government objectives, in addition to quality programmes, tertiary education institutions also put a significant amount of resources into arranging co-curricular activities (CCA) for students. With the new system, the involvement of students in CCA is implanted when they are in senior secondary schools where they have to take Other Learning Experience such as moral and civic education, community services, career-related experiences, and aesthetic and physical development. Therefore joining CCA is not a new or strange thing to tertiary education students.

Based on previous research studies, it is in general agreed that CCA brings benefits to students, and only a few studies have been done to investigate perceptions on CCA from students' point of view. Furthermore, most previous studies have been conducted in a western context. As the cultural background between the east and the west is different, it is interesting to study the perceptions in an eastern context. Hong Kong is an education hub in the east. With the new 3-3-4 education system, tertiary education institutions in Hong Kong have started putting more emphasis on holistic development with a view to nurturing the younger generation with both academic excellence and a comprehensive outlook through a broad spectrum of activities. With the change of emphasis to nurture, this study investigates the students' perceptions of CCA in Hong Kong, an eastern international city and education hub, and provides insights to tertiary educations in planning activities for students. 


\section{Literature Review}

\subsection{Co-Curricular Activities (CCA)}

To be a "whole student", both activities and academic curriculum have equal standing, and the activities do not stand on the periphery of the student's life as an extra element. In the studies of German (1995), Clements (1974) and Mathiasen (1985), the word "co-curricular" is regarded as more appropriate, and outstanding students usually achieve good academic results and participate in a greater number of non-academic activities. Therefore CCA is a broad term and can encompass campus-wide activities, sports, arts, student clubs, departmental or programme activities and activities organized by Student Affairs Office.

\subsection{Astin's Involvement Theory}

According to Astin's theory of involvement, student involvement refers to quality and quantity of the physical and psychological energy that students invest in college experience (Astin, 1999). The involvement includes absorption in academic work, participation in extracurricular activities and interaction with institutional personnel. The greater is the student involvement in schools, the greater is the amount of student learning and personal development (Astin, 1999). The theory focuses on the importance of holistic experience. Astin believes that success is the sum of total experience including learning and development which may occur inside and outside the classroom.

\subsection{Chickering's Personal Development Theory}

Chickering's (1969) psychosocial development theory proposed seven directions along which traditional college students develop. These include achieving intellectual, physical and social competence, managing emotions, becoming autonomous, establishing identity, freeing interpersonal relationships, clarifying purposes, and developing integrity. Chickering agrees with Astin that the success of a student in terms of whole-person development should be cognitive (academic performance), affective (satisfaction and self-concept), and behavioral (ability to manage emotions and independence).

\subsection{Advantages of Joining CCA}

\subsubsection{Academic Performance}

Academic performance is defined as grade point average, test scores, and educational aspirations and attainment. Some studies have documented that CCA have a positive impact on students' academic performance and commitment (Hawkins, 2010; Dumais, 2009; Lawhorn, 2009; Gardner et al., 2008; Tan \& Pope, 2007; Darling et al., 2005; Huang and Chang, 2004; George, 2002; Eccles \& Barber, 1999; Jordan \& Nettles, 1999). The cognitive and social skills required by CCA participation carry over into classroom in positive ways and therefore affect academic performance directly (Carnegie Corporation of New York, 1992). Activities also enhance students' behavioral adjustment and social-emotional competencies and attitudes which improve academic performance (Durlak et al., 2011). Students are more confident and try harder and persist in the face of challenges (Aronson, 2002). According to a study by Rose (2000), students who are heavily involved in CCA tend to be school leaders and model students.

\subsubsection{Retention Rate}

Some previous studies have showed that students' involvement in CCA made it more likely they will stay in school and improve retention rates. The study by Davalos, Shavez, and Guardiola (1999) suggested that involvement in CCA may create a sense of belonging that contributes to higher retention rates. Mahoney \& Stattin (2000) also shared a similar view that higher involvement in CCA may lower dropout rates.

A positive attitude and commitment towards schools is also developed by participating in CCA (Darling et al., 2003; Newmann, 1998). Participating in CCA can enhance students' bonding and connections to school and increase positive network ties to both teachers and other schoolmates (McNeal, 1995).

\subsubsection{Socializing}

Participation in CCA, particularly sports, can build friendship and social support with teammates (Broh, 2002) and reduce negative emotions such as loneliness or boredom (Shernoff \& Vandell, 2007). Joining CCA also facilitates socializing, which can serve as a good platform for learning cultural norms, exploring roles, developing social and emotional self-regulation (Larson \& Verma, 1999). In schools with different ethnic groups, participation in CCA facilitates the development of positive relations across ethnic groups (Khmelkov \& Hallinan, 1999). Participating in CCA provides opportunities to form friendships and develop social skills (Lawhorn, 2009; Yin \& Lei, 2007). 


\subsubsection{Competency Skills}

A field survey by Abdul et al. (2005) on teachers' perceptions of the correlation between participation of students in CCA and their competency skills, showed that those students who participate actively in CCA are found to be more competent in communication skills, cognitive skills, self-management skills and academic performance. CCA also provide opportunities for students to learn teamwork, and apply academic skills in other areas for holistic development (Arkansas Activities Association, 2004). In an informal learning environment, students can build confidence, have better time management and gain a feeling of accomplishment (Denson et al., 2015).

Participating in CCA, especially organized sports, provides an opportunity for initiative, emotional regulation, persistence, problem solving and time management, which may in turn lead to better academic achievement (Larson et al., 2006). Participating in arts activities may enhance students' creativity, imagination, fluency, and critical and divergent thinking (Burton et al., 2000).

\subsubsection{Youth Development}

Scholars who have studied youth development suggest that participation in CCA facilitates positive youth development and prevents emergence of developmental problems (Eccles et al., 2003; Eccles \& Gootman, 2002). Developmentalists and youth advocates argue that organized and constructive CCA provide students with opportunities to acquire and practice social, intellectual and physical skills that may help students contribute to the well-being of their community, establish supportive social networks, deal with challenges, and nurture a sense of belonging to a socially recognized and valued group.

Some sociological and child development studies have shown that more CCA participation results in less involvement in delinquent and risky behaviors (Durlak et al., 2011; Eccles et al., 2003; Landers \& Landers, 1978). Students who are actively involved in CCA are seldom involved in crime (Ross, 2000), use of drugs (Darling et al., 2003) and cigarette smoking (Darling, 2005).

\subsubsection{Employment}

Employers also share similar views on the importance and usefulness of CCA. The majority of employers prefer job applicants who attach a co-curricular transcript to their job application because employers believe involvement in CCA can help students develop the skills they want (Bryan et al., 1981). Therefore participation in CCA will in turn increase employability.

Yusoff et al. (2012) indicate that leaders in government and industry have called for graduates to possess employability skills associated with communication, teamwork, problem solving and decision making. Batool et al. (2012) have also indicated that employers are seeking graduates with creativity, remarkable and future-oriented thinking and high adaptability. Beheshtifar et al. (2012) suggest that learning and innovation are also important, and education institutions should be resourceful in promoting CCA to develop cognitive and affective domains that will enhance the skills of the graduates for their employment. Laguador (2013) suggests that CCA can serve as students' training ground, leading to their goal of achieving excellence in their future career.

To sum up, participation in CCA is linked to an increasing self-concept, general competency, academic performance, school engagement, mental health during youth development and better job quality (Elder \& Conger, 2000; Marsh \& Kleitman, 2002; Barber et al., 2001).

\subsubsection{Holistic Development of Students in Hong Kong}

Providing diverse and rich choices and promoting whole-person development are the core features of the new education system (Education Bureau, 2012). Apart from providing a wide range of subjects that cover the core learning areas, most secondary schools arrange a wide range of CCA so as to offer sufficient basic knowledge for students and provide them skills to face the challenges ahead. Graduates of HKDSE are in general one year younger than previous Hong Kong Advanced Level students. The new HKDSE graduates are expected to be one year younger and have experience in CCA when they enter tertiary education.

CCA appears to provide students with opportunities to achieve autonomy, skill development and relatedness, which are the three core motivational forces in human nature according to developmental psychologists (Shernoff \& Vandell, 2007; Ryan \& Deci, 2000). CCA has been advocated and supported in most western studies. Now, with the changes in background and training emphasis of tertiary education students in Hong Kong, an eastern education hub, it is important to understand the perceptions of students who participate in CCA in order to provide insights for tertiary institutions planning their CCA and resources allocation, to determine whether the findings in the west are applicable in an eastern context. 
The aim of this study is to obtain data on students' perceptions on joining CCA in order to help tertiary institutions formulate better planning in arranging activities with reference to types, timing and duration. This will then have resources implications for the institutions. In the 2010 Education Reform in Hong Kong, it applies also to tertiary education which covers degree programmes of universities and sub-degree programmes of community colleges. Sub-degree students are those who do not meet the requirements of degree studies and cannot enter degree studies They will then usually take and use sub-degree studies (either Associate Degree or Higher Diploma) as a stepping stone, entering degree studies two years later if they fulfil academic and interview requirements at that time. Degree students are those who meet the requirements of degree studies and enter degree studies strictly from secondary schools. As the sub-degree students have to jump one more hurdle before entering degree studies, their academic and psychological situation may be different from that of the degree students who enter degree studies strictly from secondary school. Their perceptions on CCA may be different. A comparison of perceptions between degree and sub-degree students will be considered to provide insights into institutions offering two different types of study.

Specific objectives of this study are:

- To investigate the interest of students in joining CCA,

- To study the students understanding of CCA,

- To identify the preferred types of CCA by students, and

- To investigate the expected usefulness of joining CCA perceived by students.

\section{Research Method}

This study is based on primary data. With reference to Shernoff and Vandell (2007) and Wong and Wong (2013), a questionnaire with four parts is used to collect data from students. Part one asks about personal information of students. Part two consists of ten questions asking about the interest of students in joining CCA, students' understanding of CCA and their preferred type / duration / timing of joining CCA. The seven types of activities listed in the questions make reference to those offered in one education institution in Hong Kong. Part three consists of two questions with 7-point Likert scales (ranging from strongly disagree to strongly agree), asking participants to rank a list of statements that represent their perceptions on the usefulness of CCA and reasons for not joining CCA. Part four is an open-ended question asking their general views or comments on CCA. To conduct the analysis, T-test, Chi-square test and z-test were used and correlation and frequency were computed.

450 survey forms were distributed to sub-degree (associate degree and higher diploma) and degree students by random of two education institutions in Hong Kong. One institution is one of the key market leaders in the sub-degree sector and provides about 500 college-wide and programme/subject activities each year to students. Another institution is a top university in Hong Kong and Asia, which offers degree places and has a unique college system to facilitate students' participation in CCA. 442 respondents returned the completed questionnaires. After removing the incomplete responses, the completed questionnaires amounted to 435 . The profile of the respondents is shown in Table 1: $57.2 \%(\mathrm{n}=249)$ were sub-degree students and $42.8 \%(\mathrm{n}=186)$ were degree students. Majority of the students were between age 18 to $25(98.4 \%)$, and were Year 1 and 2 students (95.4\%). 57.4\% were business students. Table 2 shows the correlation among choices of all valid respondents.

Table 1. Profile of Respondents (in frequency)

\begin{tabular}{llll}
\hline Sample Size & Total & Degree & Sub-Degree \\
$\mathrm{N}$ & 435 & 185 & 249 \\
\hline Gender & Total & Degree (\%) & Sub-Degree (\%) \\
Male & 48.3 & 54.8 & 43.1 \\
Female & 51.7 & 45.2 & 56.9 \\
\hline Age & Total & Degree & Sub-Degree \\
Below 18 & 1.4 & 1.6 & 1.2 \\
18-25 & 98.4 & 97.8 & 98.8 \\
Above 25 & 0.2 & 0.5 & 0 \\
\hline School Year & Total & Degree & Sub-Degree \\
Year 1 & 45.2 & 19.9 & 64.4 \\
Year 2 & 50.2 & 69.9 & 35.6 \\
\hline
\end{tabular}




\begin{tabular}{llll}
\hline Year 3 & 4.6 & 10.2 & 0 \\
Year 4 & 0 & 0 & 0 \\
\hline Specialization & Total & Degree & Sub-Degree \\
Business & 57.4 & 72.0 & 46.6 \\
Social Science/Communications & 18.4 & 9.7 & 25.1 \\
Science/Tech & 22.6 & 18.3 & 25.5 \\
Others & 1.6 & 0 & 2.8 \\
\hline
\end{tabular}

Table 2. Correlations among choices: all students

\begin{tabular}{|c|c|c|c|c|c|c|c|c|c|c|c|c|c|c|c|c|c|c|c|c|}
\hline & \multicolumn{4}{|c|}{ Part 1} & \multicolumn{6}{|c|}{ Part 2} & \multicolumn{10}{|c|}{ Part 3} \\
\hline & Q1 & Q2 & 3 & Q4 & Q1 & Q3 & Q4 & Q5 & Q6 & Q10 & $\mathrm{a}$ & $11 \mathrm{~b}$ & $11 \mathrm{c}$ & $\mathrm{d}$ & $11 \mathrm{e}$ & Q12a & $\mathrm{Q} 12 \mathrm{~b}$ & $12 \mathrm{c}$ & $12 \mathrm{~d}$ & Q12e \\
\hline Q1 & 1.000 & -0.052 & 064 & 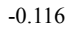 & 7 & 31 & 4 & -0 & 4 & 0.069 & 3 & 4 & 4 & 0. & 6 & 6 & .122 & .026 & .093 & .015 \\
\hline Q2 & -0.052 & 1.000 & 0.062 & 0.005 & 065 & 0.018 & 0.046 & 0.005 & 0.047 & 0.058 & -0.047 & -0.063 & -0.035 & -0.073 & 0.025 & .039 & 0.091 & 0.100 & .040 & 0.034 \\
\hline Q3 & -0.064 & 0.062 & 1. & 0.472 & 1 & 21 & 0.016 & -0.069 & 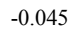 & 0 & 39 & -0 & $0 \% 0$ & 0 & 001 & 18 & 0.035 & 60 & 05 & 0.035 \\
\hline Q4 & -0.116 & 0. & 0 & 1.000 & 35 & 073 & -0.049 & -0.025 & 99 & 0 & 72 & 006 & 0.163 & 0. & 8 & 8 & 0.035 & 10 & 089 & -0.0 \\
\hline Q1 & -0.077 & 0.065 & -0.041 & -0.035 & 1.000 & 0.441 & 0.386 & 0.455 & -0.057 & -0.022 & 0.019 & -0.046 & -0.070 & -0.049 & -0.006 & 0.007 & 0.140 & 0.157 & 0.081 & 0.105 \\
\hline Q3 & -0.031 & 0.018 & -0.021 & . & 171 & 1.000 & 0.423 & 0.30 & -0.062 & -0.136 & -0.125 & -0.185 & -0.174 & -0.140 & -0.097 & 0.008 & 0.027 & 190 & .091 & 0.141 \\
\hline Q4 & -0.084 & 0.046 & 016 & 049 & 386 & 0.42 & 1000 & 28 & -0.071 & 020 & -0.017 & -0.161 & -0.132 & -0.085 & -0.082 & -0.002 & .069 & .109 & .068 & 02 \\
\hline Q5 & -0.025 & 0.005 & -0.069 & -0.025 & 0.455 & 0.396 & 0.282 & 1.000 & n.a. & 0.078 & -0.022 & -0.117 & -0.051 & -0.074 & -0.047 & 0.019 & 0.062 & 0.121 & 0.043 & 0.047 \\
\hline Q6 & -0.004 & 0. & -0.045 & -0.099 & 57 & 62 & -0.071 & 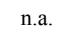 & 1.000 & 0. & 48 & -0.025 & 0.049 & 0. & -0.029 & 10 & 38 & -0.070 & 132 & -0 \\
\hline Q10 & 0.069 & 0.058 & 0.083 & 0.144 & -0.022 & -0.136 & 0.029 & 0.078 & 0.141 & 1.000 & 0.001 & 0.117 & 0200 & 0.183 & 0.160 & 0.056 & 0.155 & -0.065 & -0.096 & -0.05 \\
\hline Q11a & -0.073 & -0.047 & -0.039 & 0.072 & 0.019 & -0.125 & -0.017 & -0.022 & -0.048 & 0.001 & 1.000 & 0.510 & 0.415 & 0.344 & 0.285 & -0.068 & 0.060 & -0.067 & -0.038 & -0.052 \\
\hline Q11b & 0 & -0.063 & -0.023 & 0.005 & -0 & -0.185 & -0.161 & -0 & -0.025 & 0.117 & 0.510 & 1. & 0.665 & 0 & 0.549 & 9 & 9 & 0 & 27 & -0 \\
\hline Q11c & 0.064 & -0.035 & 0.098 & 163 & -0.070 & -0.174 & -0.132 & -0.051 & 0.049 & 0.200 & 0.415 & 0.665 & 1.000 & 0.702 & 0.609 & 0.156 & 0.082 & 0.006 & 0.063 & -0.033 \\
\hline Q11d & 0.042 & -0.073 & 0.049 & 0.060 & -0.049 & -0.140 & -0.085 & -0.074 & 0.054 & 0.183 & 0.344 & 0.589 & 0.702 & 1.000 & 0.796 & 0.162 & 0.092 & 0.006 & 0.049 & -0.021 \\
\hline Q11e & 0.106 & 0025 & 0.007 & 050 & -0.006 & -0.097 & -0.082 & -0.047 & (2000 & 0.16 & 02 & $0<-2$ & 06 & 0. & 0 & 0 & 0. & 26 & 2 & 0. \\
\hline Q12a & 0.116 & 0.039 & 0.018 & -0.158 & 0.007 & 0.008 & -0.002 & 0.019 & -0.010 & 0.056 & -0.068 & 0.189 & 0.156 & 0.162 & 0.270 & 1.000 & 0.301 & 0.256 & 0.317 & 0.316 \\
\hline Q12b & 0.122 & 0.091 & 0.035 & 0.035 & 0.140 & 0.027 & 0.069 & 0.062 & -0.138 & 0.155 & 0.060 & 0.119 & 0.082 & 0.092 & 0.183 & 0.301 & 1.000 & 0.313 & 0.292 & 0.280 \\
\hline Q12c & -0.026 & 0.100 & 60 & 0.010 & 57 & 90 & 0 & 0.121 & 70 & -0 . & 67 & -0 . & 0.006 & 0 & 26 & 6 & 3 & 00 & 0.510 & 0. \\
\hline Q12d & 0.093 & 0.040 & 0.005 & -0.089 & 0081 & 0.091 & 0.068 & 0043 & -0.132 & -0.096 & -0.038 & 0.027 & 0.063 & 0.049 & 0.072 & 0.317 & 0.292 & 0.510 & 1.000 & 0.509 \\
\hline Q12e & 0.015 & 0.034 & 0.035 & -0.011 & 0.105 & 0.141 & 0.102 & 0.047 & -0.074 & -0.055 & -0.052 & -0.050 & -0.033 & -0.021 & 0.019 & 0.316 & 0.280 & 0.529 & 0.509 & 1.000 \\
\hline
\end{tabular}

\section{Results}

\subsection{Interest of Students in Joining CCA}

Most sub-degree and degree students showed an interest in participating in CCA (68.3\% and $75 \%$ respectively) and agreed that their institutions should provide CCA ( $78.2 \%$ and $82.2 \%$ respectively). $56 \%$ of sub-degree students indicated that they had participated in CCA at their institutions, and the majority of them (80.3\%) indicated that they participated in one to two activities at one time. Regarding degree students, $58.6 \%$ indicated that they had participated in CCA and the majority of them (86.5\%) participated in one to two activities at one time.

Among the seven types of activity, the three most popular activities sub-degree students enjoyed were further studies and career development (39\%), growth and development $(24.9 \%)$, and service learning (15.7\%). For degree students, these three were also the most popular CCA. For degree students, growth and development was their top priority $(29.8 \%)$, service learning $(25.6 \%)$ was second and further studies and career development $(19.5 \%)$ was the third.

\subsection{Students Understanding of CCA}

Most sub-degree and degree students indicated that they had heard about CCA at their education institutions (64.4\% and $67.7 \%$ respectively). The channels through which sub-degree students got CCA information were mainly emails (40.2\%), leaflets and posters (21.3\%) and teachers and counsellors (17.6\%). For degree students, the three most popular channels through which they received CCA information were the same as those of the sub-degree students but the ranking was different. Degree students got information mostly from teachers and counsellors (26\%). The second most popular means was leaflets and posters $(25.2 \%)$, and the third was emails (24.4\%). Sub-degree students commented that email was convenient and they received a lot every day. 


\subsection{Relationship between Interest and Understanding}

To both sub-degree students and degree students, the result showed a high positive correlation between students' understanding and interest in CCA $(\mathrm{Q} 1$ and Q3: $\mathrm{r}=0.44854$; Q1 and Q5: $\mathrm{r}=0.442107$ for sub-degree) (Table 3 Correlation among choices: sub-degree students) $(\mathrm{Q} 1$ and $\mathrm{Q} 3$ : $r=0.43699$; $\mathrm{Q} 1$ and $\mathrm{Q}$ 5: $\mathrm{r}=0.479866$ for degree students) (Table 4 - Correlation among choices: degree students).

Sub-degree students who were interested in CCA also preferred schools to provide CCA for them (Q3 and Q4: $\mathrm{r}$ $=0.429104)$. The correlation coefficient of $\mathrm{Q} 1$ and $\mathrm{Q} 4$ in sub-degree students was also high $(\mathrm{r}=0.439586)$, while the correlation coefficient of the two questions in the whole sample was only 0.385571 . Sub-degree students who had heard about CCA at school preferred schools to provide CCA for them (Table 3).

The correlation coefficient of Q3 and Q5 in degree students was high $(\mathrm{r}=0.512403)$, while in sub-degree students the correlation coefficient was just 0.312557 . Degree students who showed an interest in CCA had more chance to participate in CCA (Table 4).

\section{4 Preferred CCA}

Sub-degree students preferred study tour and exchange (41\%), further studies and career development (30\%), and growth and development $(20 \%)$ most among the seven choices. The top priority was study tour and exchange. Sub-degree students preferred further studies and career development to growth and development activities. There was a significant difference between study tour and exchange and other choices $(\mathrm{p}<0.05)$ among sub-degree students.

For degree students, study tour and exchange was also their first choice (35.8\%). However, the second and third preferred choices were growth and development $(33.3 \%)$ and service learning $(14.8 \%)$, which was different to that of the sub-degree students. There was a significant difference between study tour and exchange and the other choices $(\mathrm{p}<0.05)$ among degree students. Service learning ranked higher for degree students because service learning is a requirement for degree students for graduation.

The most preferred timing sub-degree students would like to participate in CCA was June to August, about half of the respondents $(50.9 \%)$ preferring this period. The next preferred time was September to November (19.9\%). The least preferred time was May (5.8\%). There was a significant difference between June to August and other choices $(\mathrm{p}<0.05)$. The second least preferred time of sub-degree students was December $(7.5 \%)$. This may be because December is the examination period of semester one and sub-degree students have to study hard in order to gain a higher grade point average for articulation into degree studies. The same issue also affects May as it is the month for the semester 2 examinations. Therefore it is the least preferred time for activities for sub-degree students.

For degree students, June to August (44\%) and September to November (17.7\%) were also the top two preferred timings, while the third choice was December $(14.9 \%)$. There was a significant difference between June to August and the other choices $(\mathrm{p}<0.05)$. The least preferred time was January $(6.3 \%)$. This may be due to the shortening of the semester break in degree studies or the fact that degree students are busy with job interviews. June to August was the most popular choice for sub-degree and degree students because they have a summer holiday and may have more time for CCA.

Both groups of students commented that they would love to join a study tour but it was expensive and took more time. It would be good if schools could subsidize them and arrange tours in the summer.

If sub-degree students had to participate in an activity, the two most preferred durations were one to three hours $(39.5 \%)$ and across one week (27.2\%) The one least preferred was an activity across two semesters $(2.1 \%)$. There was a significant difference among the choices; one to three hours was the most popular one $(p<0.05)$ among sub-degree students. The results were very close to that of the degree students in these aspects. However, the third preferred duration was different. The third place for sub-degree students was one day, while for the degree students it was one semester. Sub-degree students preferred one day more than one semester. They preferred activities with a shorter duration while degree students could afford a longer duration.

For degree students, the top three choices were one to three hours $(28.1 \%)$, across one week $(25.8 \%)$ and across one semester $(24.2 \%)$. There was a significant difference among the choices. One to three hours was the most popular one $(\mathrm{p}<0.05)$ among degree students.

\subsection{Perceptions on Usefulness of CCA}

More than $50 \%$ of sub-degree students agreed that CCA would help increase further study opportunities, increase job opportunities, brush up presentation skills, and brush up interview skills. Increase in further studies 
opportunities (62.4\%) scored the highest percentage of agreement among sub-degree students. Their priorities were: increase further study opportunities, brush up interview skills, brush up presentation skills, increase job opportunities, and upgrade grade point average. To sub-degree students, the second most important factor was brushing up interview skills. Sub-degree students perceived that CCA could help them succeed in interviews in order to get places on degree programmes.

For sub-degree students, all the five suggested reasons for joining CCA have a high positive correlation between each other (all $r>0.5$ ) (Table 3). The results showed students who gave high (low) score in any one factor would also give high (low) score in other factors. Therefore, five factors are dependent factors. Sub-degree students who wanted to participate in CCA related to their academic studies and career and would also like these activities could increase further study opportunities, brush up interview skills and presentation skills.

Increasing job opportunities (69.9\%) scored the highest percentage of agreement among degree students. The average score for degree students of this choice was significantly not equal to that of sub-degree students. This may be because getting a job is the first priority of degree students after graduation. Their priorities were increasing job opportunities, increasing further study opportunities, brushing up presentation skills, brushing up interview skills, and upgrading the grade point average. By using two sample z-tests, it is interesting to find that the percentages in agreement with three of the five reasons (except increasing further study opportunities and brushing up interview skills) were higher in degree students than in sub-degree students. It indicates that more degree students considered CCA to be helpful in different aspects.

For degree students, the factor increasing job opportunities has an extremely high positive correlation between other three factors: increasing further study opportunities, brushing up presentation skills and improving interview skills (all $r>0.6$ ) (Table 4). The result showed degree students who wanted to participate in CCA related to their career and would also like these activities could increase further study opportunities and brush up interview skills and presentation skills.

\subsection{Reasons for Not Joining CCA}

Most sub-degree and degree students (64\% and $48.6 \%$ respectively) agreed that they had to spend more time studying and could not join CCA. The priority for sub-degree students was: more time needed to study, no accompany friends, CCA may not be useful, fees too high, and lack of interest. Sub-degree students commented that study was very important. The priority for degree students was: more time needed to study, high fees, no accompanying friends, lack of usefulness, and lack of interest.

About $26 \%$ to $40 \%$ of sub-degree students rated slightly agree to strongly agree for the other four reasons while the range among degree students was $30 \%$ to $35 \%$. The agreement responses of degree students were quite even among the five reasons for not joining CCA. The results show that degree students did not have strong views about not participating in CCA. Among the five suggested reasons, lack of interest was the reason with the lowest support among both sub-degree and degree students ( $25.9 \%$ and $29.8 \%$ respectively).

The factor relating to lack of interest in participating has a high correlation with two other factors: no accompanying friends and skepticism about usefulness $(\mathrm{r}=>0.5)$ (Table 3). Sub-degree students who were not interested in CCA tended to focus on the lack of usefulness and absence of friends.

The factor regarding friends has a high correlation with the other four factors (all $r=>0.4$ ) (Table 4) for degree students. Degree students who could not find friends to accompany them to CCA would tend not to attend.

\section{Discussions and Recommendations}

\subsection{Interest and Types of CCA}

Both sub-degree and degree students are interested in participating in CCA and agree that their schools should provide CCA. Consistent with the study of Ismat and Rakhsi on stakeholders' perceptions about the role of CCA, the majority of the respondents have joined CCA one way or the other. Also consistent with the study of Agnihotri and Sikka (2013) and Mawi and Maisnam (2014), the majority of the students perceive that they should participate in CCA organized in schools and are interested in the CCA the schools provide respectively. Therefore tertiary institutions should continue to provide CCA to students.

However, the focus of the types of CCA provided may be different for sub-degree and degree students. Based on what students have joined, sub-degree education institutions can consider providing more activities on further studies and career development (e.g. career and study talks, job placement, celebrity talks). The activity most sub-degree students participated in is different from the one they most preferred. They prefer study tours and exchanges more but in practice they joined further studies and career development. This may be due to the time 
and money involved in tours, and the perceived usefulness of further studies and career development. Some sub-degree students commented that study tours and exchanges require them to invest more time and financial support. They may not be able to afford it because they have to concentrate on studies in order to achieve a higher grade point average to pursue degree study. In Hong Kong, most parents prefer their children to have at least a bachelor degree in order to have competitiveness, and therefore qualification of sub-degree is not their final destination. Such belief is consistent with the result of the Hofstede Center's study about the cultural dimensions in Hong Kong: the scores for masculinity and long term orientation are high (http://geert-hofstede.com/hong-kong.html). The high score for masculinity means the society is driven by competition, achievement and success, with success being defined by the winner in the field. The value system starts in school and continues throughout working life. Students in school care very much about their exam scores and ranking as this is the main criteria to achieve success. The high score of long term orientation means the society takes a more pragmatic approach and people encourage thrift and efforts in modern education as a way to prepare for the future. Sub-degree study is considered a stepping stone, and sub-degree students have a clear study direction and goals in mind and usually work hard to achieve better academic result to enter into degree programmes (Leung et al., 2011). Sub-degree students believe training or information provided in further studies and career development is useful for getting a degree place. Therefore they embraced activities relating to studies and career development instead of study tours even though they would love to take them.

Based on what degree students have joined, tertiary education providers should provide more activities relating to growth and development (e.g. mentorship, leadership training, physical education and language enhancement). Students' reasons for participating in growth and development activities may be due to a desire to widen their network, meet people and make friends. Students view participation in CCA as an avenue to develop relationships (Tamsen \& Bissonnette, 2008). CCA may enhance their skills which are important for job interviews and writing resumes. Students participate in CCA to develop leadership and other skills which can help them later on in their career (Tamsen \& Bissonnette, 2008). Consistent with the result of the Hofstede Center's study about the cultural dimensions in Hong Kong, the scores for masculinity and long term orientation are high (http://geert-hofstede.com/hong-kong.html). Good preparation will enhance competitiveness and success in the job market and future career.

Both sub-degree and degree students prefer study tours and exchanges most. Education institutions can provide more sponsorship to students to join study tours so that students can broaden their international horizons, which may be useful for their holistic development. Education institutions can also consider arranging the tours from June to August when students have their summer holiday and do not need to study so much.

\subsection{Understanding and Promotion Channels}

The majority of sub-degree and degree students heard about CCA through their education institutions. Most sub-degree students obtained the CCA information from emails (40.2\%) which is far more than the other two popular channels (leaflets/posters and teachers/counsellors). It may be due to the fact that electronic channels are more popular and well-received among sub-degree students. Sub-degree education providers can consider continuing using electronic channels such as emails or phone messages, and encourage students to read leaflets or posters and seek advice or information from teachers and counsellors.

Among degree students, the proportion of the top three popular channels is quite even, ranging from $24 \%$ to $26 \%$. Degree education providers can make use of the three channels: teachers and counsellors, leaflets and posters, and emails, to promote the activities.

The common channels where both groups of students get CCA information are consistent with those of the study of Tamsen and Bissonnette (2008). In their study, it is suggested that the activities should be advertised through as many available avenues as possible, and the advertising should be designed to appeal to student interests and mention the benefits students get after joining.

\subsection{Understanding and Interest}

Regarding sub-degree students, if they are interested in CCA, they prefer their schools to provide CCA for them. If they have heard about CCA, they are more interested in or have a higher chance of participating in CCA. Sub-degree education providers should then promote information about CCA more through electronic channels in order to attract students' interest and participation.

If degree students are interested in CCA, their chance of participating in CCA is higher. Similar to sub-degree students, if they have heard about CCA, they are more interested in taking part or have a higher chance of taking part in CCA. Degree students take action to participate in activities if they are interested in them, while 
sub-degree students prefer schools to provide CCA in the first place and they decide whether to take part or not later, even if they are interested. Sub-degree students may not take action to join. They have doubts even if they are interested. The doubts may be due to time involved or worry about academic study. Therefore, sub-degree education providers may consider incorporating activities into academic study (such as organizing subject or programme activities). Students can then pay attention to their studies and take part in activities at the same time. Leung et al. (2011) suggest that CCA should be designed and integrated with the core curriculum.

\subsection{Preferred Timing}

Sub-degree students prefer June to August and do not favour December and May. As December and May are the examination periods, sub-degree students have to pay attention to studies. Consistent with the study of Leung et al. (2011) and Tamsen and Bissonnette (2008), students do not prefer activities near examinations or when papers are due. June to August is the summer period when they take a break and have more leisure time and energy to take part in activities. Degree students also prefer June to August the most.

The least preferred timing for degree students is January. This is due to shortening of the semester break in degree studies or degree students are busy with interviews for jobs or internships. Therefore, education providers of degree studies should try to avoid arranging January activities.

\subsection{Preferred Duration}

Both sub-degree and degree students prefer one to three hours the most, and across one week the next. The third place for sub-degree students is one day while for degree students it is one semester. Nevertheless, both groups prefer the shortest duration the most. This result is consistent with that of the study of (Tamsen \& Bissonnette, 2008). Based on the top three choices of two groups, sub-degree students in general prefer a short duration more. Education institutions can try to arrange activities with shorter duration for sub-degree students. Their preferred duration is consistent with their most popular activity, further studies and career development which are usually completed within a few hours, such as study talks.

\subsection{Perceptions on Usefulness of CCA}

Sub-degree students who join CCA expect the activities to help them increase further studies and job opportunities, brush up interview and presentation skills, and improve academic results. Enhance further study opportunities is the top reason. This is consistent with their popular activity: further studies and career development which provide study talks. To benefit the sub-degree students, educational institutions can arrange more activities related to further studies and career development.

More than half of the degree students agree CCA would help increase further studies and job opportunities, and brush up interview and presentation skills. A majority of them believe CCA can help them increase job opportunities. They want to take part in activities which can help them in these four aspects. This is consistent with the activity they usually participated in: growth and development which covers the mentorship programme, leadership training and language enhancement. These elements can help them understand more about the industry or field they will join after graduation or enhance their leadership and language skills which are vital to their career development. Degree education providers should consider arranging more activities on growth and development.

In general, both groups of students perceive participation in CCA is useful and the findings are consistent with the results of Lanjewar (2014) that CCA can enhance skills and value addition.

\subsection{Reasons for Not Participating in CCA}

Both sub-degree and degree students agree that time needed to study is the most important factor for not taking part in CCA, and lack of interest is the least important reason. They fear taking part in CCA may adversely affect their studies. This result is consistent with that of the study of (Tamsen \& Bissonnette, 2008), who found that students who do not get involved in CCA are most likely spending time studying and doing their homework. Education providers should try to teach students how to have better time management in order to encourage them to participate in CCA, which in general are believed to be useful.

Sub-degree students who are not interested in CCA would tend to regard CCA as not useful and are put off by a lack of accompanying friends. Degree students whose friends do not participate with them would tend not to take part in CCA. These results show peer effect among schoolmates may have an influence on students' participation in activities. Sub-degree students have one more concern: the usefulness of CCA.

\subsection{Conclusion}

The results provide insights for education institutions in resource allocation and arranging activities. The 
majority of both groups is interested and has an understanding of CCA. Therefore providing CCA to students is essential. As the concerns and preferences of sub-degree and degree students are different in some aspects, the results provide more insights to institutions educating different groups of students. Education providers of sub-degree students can provide more on further studies and career development with more emphasis on pursuing study during the summer with shorter duration. Education institutions of degree students can provide more on growth and development with more emphasis on job hunting during the summer. If financial resources allow, both types of institutions can provide more sponsorship to students on study tours and exchanges during the summer.

Based on the results, the Student Affairs Office (SAO) and departments of schools can discuss sharing responsibility for arranging different types of activities because both sections have different expertise in arranging activities which fit students' needs. For instance, a time management workshop can be arranged by $\mathrm{SAO}$, or a company visit of certain disciplines can be arranged by departments or programmes. As both the SAO and departments share the duty of arranging activities, this may affect resource allocation among different units in schools. As both degree and sub-degree students have concerns about the time to study, departments may also consider incorporating some activities into students' subjects or programmes so that students can enjoy the benefits of participating in activities and study at the same time. Concerted efforts of student affairs professionals and academic staff will provide synergy to provide different types of activities to enhance students' whole-person development.

Table 3. Correlations among choices: subdegree students

\begin{tabular}{|c|c|c|c|c|c|c|c|c|c|c|c|c|c|c|c|c|c|c|c|c|}
\hline & \multicolumn{4}{|c|}{ Part 1} & \multicolumn{6}{|c|}{ Part 2} & \multicolumn{10}{|c|}{ Part 3} \\
\hline & Q1 & Q2 & Q3 & Q4 & Q1 & Q3 & Q4 & Q5 & Q6 & Q10 & Q11a & Q11b & Q11c & Q11d & Q11e & Q12a & Q12b & Q12c & Q12d & Q12e \\
\hline Q1 & 1.000 & -0.097 & -0.026 & \#DIV/0! & -0.196 & -0.136 & -0.111 & -0.135 & -0.036 & 0.058 & -0.006 & 0.052 & 0.052 & -0.040 & 0.035 & 0.109 & 0.028 & -0.073 & 0.054 & -0.037 \\
\hline Q2 & -0.097 & 1.000 & 0.005 & \#DIV/0! & 0.082 & 0.085 & 0.059 & 0.023 & 0.056 & -0.042 & 0.088 & 0.017 & 0.030 & -0.033 & 0.009 & -0.069 & 0.004 & 0.056 & -0.005 & -0.033 \\
\hline Q3 & -0.026 & 0.005 & 1.000 & \#DIV/0! & -0.093 & -0.058 & -0.129 & -0.199 & -0.005 & -0.038 & -0.105 & 0.002 & 0.030 & 0.039 & -0.009 & 0.072 & -0.138 & -0.040 & -0.035 & -0.052 \\
\hline Q4 & \#DIV/0! & ! \#DIV/0! & ! \#IV/0! & ! \#DIV/0! & \#DIV/0! & \#DIV/0! & \#DIV/0! & \#DIV/0! & ! \#DIV/0! & ! \#DIV/0! & \#DIV/0! & \#DIV/0! & ! \#DIV/0! & ! \#DIV/0! & \#DIV/0! & \#DIV/0! & \#DIV/0! & \#DIV/0! & \#DIV/0! & \#DIV/0! \\
\hline Q1 & -0.196 & 0.082 & -0.093 & \#DIV/0! & 1.000 & 0.449 & 0.44 & 0.442 & -0.146 & 0.012 & 0.009 & -0.077 & -0.133 & -0.081 & -0.069 & -0.056 & 0.131 & 0.126 & -0.015 & 0.091 \\
\hline Q3 & -0.136 & 0.085 & -0.058 & \#DIV/0! & 0.449 & 1.000 & 0.429 & 0.313 & -0.135 & -0.173 & -0.119 & -0.225 & -0.249 & -0.201 & -0.150 & -0.036 & 0.024 & 0.185 & 0.043 & 0.151 \\
\hline Q4 & -0.111 & 0.059 & -0.129 & \#DIV/0! & 0.440 & 0.429 & 1.000 & 0.261 & -0.174 & 0.064 & 0.044 & -0.078 & -0.099 & -0.046 & -0.080 & -0.021 & 0.124 & 0.097 & 0.026 & 0.068 \\
\hline Q5 & -0.135 & 0.023 & -0.199 & \#DIV/0! & 0.442 & 0.313 & 0.261 & 1.000 & n.a. & 0.095 & -0.035 & -0.199 & -0.088 & -0.133 & -0.134 & 0.006 & 0.054 & 0.074 & 0.040 & 0.059 \\
\hline Q6 & -0.036 & 0.056 & -0.005 & \#DIV/0! & -0.146 & -0.135 & -0.174 & n.a. & 1.000 & 0.118 & -0.020 & 0.040 & 0.078 & 0.066 & -0.111 & -0.096 & -0.167 & -0.171 & -0.261 & -0.229 \\
\hline Q10 & 0.058 & -0.042 & -0.038 & \#DIV/0! & 0.012 & -0.173 & 0.064 & 0.095 & 0.118 & 1.000 & 0.203 & 0.122 & 0.210 & 0.206 & 0.165 & 0.056 & 0.133 & -0.119 & -0.080 & -0.135 \\
\hline Q11a & -0.006 & 0.088 & -0.105 & \#DIV/0! & 0.009 & -0.119 & 0.044 & -0.035 & -0.020 & 0.203 & 1.000 & 0.557 & 0.515 & 0.501 & 0.530 & 0.041 & 0.180 & -0.064 & 0.041 & -0.059 \\
\hline Q11b & 0.052 & 0.017 & 0.002 & \#DIV/0! & -0.077 & -0.225 & -0.078 & -0.199 & 0.040 & 0.122 & 0.557 & 1.000 & 0.678 & 0.625 & 0.630 & 0.322 & 0.117 & -0.036 & 0.077 & -0.146 \\
\hline Q11c & 0.052 & 0.030 & 0.030 & \#DIV/0! & -0.133 & -0.249 & -0.099 & -0.088 & 0.078 & 0.210 & 0.515 & 0.678 & 1.000 & 0.653 & 0.611 & 0.240 & 0.148 & 0.042 & 0.136 & -0.123 \\
\hline Q11d & -0.040 & -0.033 & 0.039 & \#DIV/0! & -0.081 & -0.201 & -0.046 & -0.133 & 0.066 & 0.206 & 0.501 & 0.625 & 0.653 & 1.000 & 0.789 & 0.243 & 0.153 & 0.049 & 0.131 & -0.077 \\
\hline Q11e & 0.035 & 0.009 & -0.009 & \#DIV/0! & -0.069 & -0.150 & -0.080 & -0.134 & -0.111 & 0.165 & 0.530 & 0.630 & 0.611 & 0.789 & 1.000 & 0.272 & 0.207 & 0.022 & 0.078 & -0.089 \\
\hline Q12a & 0.109 & -0.069 & 0.072 & \#DIV/0! & -0.056 & -0.036 & -0.021 & 0.006 & -0.096 & 0.056 & 0.041 & 0.322 & 0.240 & 0.243 & 0.272 & 1.000 & 0.215 & 0.202 & 0.228 & 0.162 \\
\hline Q12b & 0.028 & 0.004 & -0.138 & \#DIV/0! & 0.131 & 0.024 & 0.124 & 0.054 & -0.167 & 0.133 & 0.180 & 0.117 & 0.148 & 0.153 & 0.207 & 0.215 & 1.000 & 0.287 & 0.200 & 0.237 \\
\hline $\mathrm{Q} 12 \mathrm{c}$ & -0.073 & 0.056 & -0.040 & \#DIV/0! & 0.126 & 0.185 & 0.097 & 0.074 & -0.171 & -0.119 & -0.064 & -0.036 & 0.042 & 0.049 & 0.022 & 0.202 & 0.287 & 1.000 & 0.493 & 0.619 \\
\hline Q12d & 0.054 & -0.005 & -0.035 & \#DIV/0! & -0.015 & 0.043 & 0.026 & 0.040 & -0.261 & -0.080 & 0.041 & 0.077 & 0.136 & 0.131 & 0.078 & 0.228 & 0.200 & 0.493 & 1.000 & 0.485 \\
\hline Q12e & -0.037 & -0.033 & -0.052 & \#DIV/0! & 0.091 & 0.151 & 0.068 & 0.059 & -0.229 & -0.135 & -0.059 & -0.146 & -0.123 & -0.077 & -0.089 & 0.162 & 0.237 & 0.619 & 0.485 & 1.000 \\
\hline
\end{tabular}

Table 4. Correlations among choices: degree students

\begin{tabular}{|c|c|c|c|c|c|c|c|c|c|c|c|c|c|c|c|c|c|c|c|c|}
\hline & \multicolumn{4}{|c|}{ Part 1} & \multicolumn{6}{|c|}{ Part 2} & \multicolumn{10}{|c|}{ Part 3} \\
\hline & Q1 & Q2 & Q3 & Q4 & Q1 & Q3 & Q4 & Q5 & Q6 & Q10 & Q11a & Q11b & Q11c & Q11d & Q11e & Q12a & Q12b & Q12c & Q12d & Q12e \\
\hline Q1 & 1.000 & -0.007 & 0.023 & \#DIV/0! & 0.067 & 0.107 & -0.051 & 0.126 & -0.011 & 0.136 & -0.138 & 0.195 & 0.124 & 0.171 & 0.179 & 0.078 & 0.261 & 0.029 & 0.114 & 0.087 \\
\hline Q2 & -0.007 & 1.000 & 0.123 & \#DIV/0! & 0.051 & -0.043 & 0.034 & -0.013 & 0.036 & 0.161 & -0.169 & -0.144 & -0.098 & -0.115 & -0.056 & 0.147 & 0.179 & 0.146 & 0.090 & 0.097 \\
\hline Q3 & 0.023 & 0.123 & 1.000 & \#DIV/0! & 0.060 & 0.081 & 0.240 & 0.082 & -0.014 & 0.081 & -0.056 & -0.052 & 0.034 & 0.007 & 0.098 & 0.163 & 0.208 & 0.198 & 0.183 & 0.123 \\
\hline Q4 & \#DIV/0! & \#DIV/0! & \#DIV/0! & \#DIV/0! & \#DIV/0! & \#DIV/0! & \#DIV/0! & \#DIV/0! & \#DIV/0! & \#DIV/0! & \#DIV/0! & \#DIV/0! & \#DIV/0! & \#DIV/0! & \#DIV/0! & \#DIV/0! & \#DIV/0! & \#DIV/0! & \#DIV/0! & \#DIV/0! \\
\hline Q1 & 0.067 & 0.051 & 0.060 & \#DIV/0! & 1.000 & 0.437 & 0.317 & 0.480 & 0.095 & -0.054 & 0.037 & -0.007 & 0.017 & 0.000 & 0.067 & 0.070 & 0.156 & 0.190 & 0.203 & 0.131 \\
\hline Q3 & 0.107 & -0.043 & 0.081 & \#DIV/0! & 0.437 & 1.000 & 0.397 & 0.512 & 0.064 & -0.070 & -0.122 & -0.122 & -0.052 & -0.049 & -0.031 & 0.056 & 0.038 & 0.216 & 0.164 & 0.115 \\
\hline Q4 & -0.051 & 0.034 & 0.240 & \#DIV/0! & 0.317 & 0.397 & 1.000 & 0.302 & 0.124 & -0.013 & -0.085 & -0.275 & -0.157 & -0.138 & -0.086 & 0.020 & -0.003 & 0.148 & 0.145 & 0.131 \\
\hline Q5 & 0.126 & -0.013 & 0.082 & \#DIV/0! & 0.480 & 0.512 & 0.302 & 1.000 & n.a. & 0.067 & -0.001 & -0.001 & 0.006 & 0.008 & 0.065 & 0.034 & 0.077 & 0.196 & 0.053 & 0.020 \\
\hline
\end{tabular}




\begin{tabular}{ccccccccccccccccccccc}
\hline Q6 & -0.011 & 0.036 & -0.014 & \#DIV/0! & 0.095 & 0.064 & 0.124 & n.a. & 1.000 & 0.237 & -0.080 & -0.154 & 0.043 & 0.037 & 0.066 & 0.085 & -0.082 & 0.084 & 0.070 & 0.166 \\
Q10 & 0.136 & 0.161 & 0.081 & \#DIV/0! & -0.054 & -0.070 & -0.013 & 0.067 & 0.237 & 1.000 & -0.254 & 0.114 & 0.145 & 0.138 & 0.180 & 0.114 & 0.175 & 0.003 & -0.090 & 0.038 \\
Q11a & -0.138 & -0.169 & -0.056 & \#DIV/0! & 0.037 & -0.122 & -0.085 & -0.001 & -0.080 & -0.254 & 1.000 & 0.459 & 0.292 & 0.152 & 0.026 & -0.162 & -0.088 & -0.075 & -0.120 & -0.040 \\
Q11b & 0.195 & -0.144 & -0.052 & \#DIV/0! & -0.007 & -0.122 & -0.275 & -0.001 & -0.154 & 0.114 & 0.459 & 1.000 & 0.666 & 0.547 & 0.452 & 0.029 & 0.120 & -0.030 & -0.044 & 0.074 \\
Q11c & 0.124 & -0.098 & 0.034 & \#DIV/0! & 0.017 & -0.052 & -0.157 & 0.006 & 0.043 & 0.145 & 0.292 & 0.666 & 1.000 & 0.766 & 0.646 & 0.118 & -0.010 & -0.046 & 0.000 & 0.080 \\
Q11d & 0.171 & -0.115 & 0.007 & \#DIV/0! & 0.000 & -0.049 & -0.138 & 0.008 & 0.037 & 0.138 & 0.152 & 0.547 & 0.766 & 1.000 & 0.823 & 0.089 & 0.008 & -0.049 & -0.048 & 0.048 \\
Q11e & 0.179 & -0.056 & 0.098 & \#DIV/0! & 0.067 & -0.031 & -0.086 & 0.065 & 0.066 & 0.180 & 0.026 & 0.452 & 0.646 & 0.823 & 1.000 & 0.253 & 0.161 & 0.028 & 0.051 & 0.149 \\
Q12a & 0.078 & 0.147 & 0.163 & \#DIV/0! & 0.070 & 0.056 & 0.020 & 0.034 & 0.085 & 0.114 & -0.162 & 0.029 & 0.118 & 0.089 & 0.253 & 1.000 & 0.439 & 0.328 & 0.411 & 0.532 \\
Q12b & 0.261 & 0.179 & 0.208 & \#DIV/0! & 0.156 & 0.038 & -0.003 & 0.077 & -0.082 & 0.175 & -0.088 & 0.120 & -0.010 & 0.008 & 0.161 & 0.439 & 1.000 & 0.347 & 0.433 & 0.337 \\
Q12c & 0.029 & 0.146 & 0.198 & \#DIV/0! & 0.19 & 0.216 & 0.148 & 0.196 & 0.084 & 0.003 & -0.075 & -0.030 & -0.046 & -0.049 & 0.028 & 0.328 & 0.347 & 1.000 & 0.534 & 0.442 \\
Q12d & 0.114 & 0.090 & 0.183 & \#DIV/0! & 0.203 & 0.164 & 0.145 & 0.053 & 0.070 & -0.090 & -0.120 & -0.044 & 0.000 & -0.048 & 0.051 & 0.411 & 0.433 & 0.534 & 1.000 & 0.569 \\
Q12e & 0.087 & 0.097 & 0.123 & \#DIV/0! & 0.131 & 0.115 & 0.131 & 0.020 & 0.166 & 0.038 & -0.040 & 0.074 & 0.080 & 0.048 & 0.149 & 0.532 & 0.337 & 0.442 & 0.569 & 1.000 \\
\hline
\end{tabular}

\section{Limitations and Future Research}

This study provides useful ideas for education institutions to plan CCA for students. However, the majority of respondents come from two schools only and the choices of activities in the questions are mainly based on the types provided in one school. The results may show some bias and cannot be generalized to draw conclusions for the overall tertiary education sector. Furthermore, this study is a horizontal one which cannot compare the perceptions of students before and after participating in CCA.

In future, similar analysis can be carried out in more schools in order to make the results more representative. The study would be even richer if analysis could be conducted across specialization or countries as well. It is worthwhile having a longitudinal study to investigate the pre and post situation of students in participating in CCA. It is also worthwhile studying how CCA would enhance students learning and its relationship with different outcomes in future.

\section{Acknowledgements}

The work described in this paper was fully supported by a grant from the College of Professional and Continuing Education, an affiliate of the Hong Kong Polytechnic University.

\section{References}

Abdul, R., Abdul, S., \& Bokkasam, S. (2005). Teachers' perception on the effectiveness of co-curricular activities: A case study of Malaysian Schools. UNITAR E-Journal, 1(1), 32-44.

Agnihotri, A. K., \& Sikka, S. (2013), Co-curricular activities as perceived by students and teachers of government secondary schools of Himachal Pradesh. Scholarly Research Journal for Interdisciplinary Studies, $1(\mathrm{~V}), 1112-1129$.

Arkansas Activities Association (n.d.). (2004). Case for high school activities. Retrieved from $\mathrm{http} / /$ :www.ahsaa.org/case-for-high-school-activities.html

Aronson, J. (2002). Improving academic achievement: Impact of Psychological factors on Education. New York: Academic Press.

Astin, A. (1984). Student involvement: A developmental theory for higher education. Journal of College Student Personnel, 25(4), 297-308.

Astin, A. (1993). What matters in College? Four critical years revisited. San Francisco: Jossey-Bass.

Astin, A. (1999). Student involvement: a developmental theory for higher education. Journal of College Student Development, 40(5), 518-529.

Barber, B. L., Eccles, J. S., \& Stone, M. R. (2001). Whatever happened to the "Jock", the "Brian", and the "Princess"?: Young adult pathways linked to adolescent activity involvement and social identity. Journal of Adolescent Research, 16, 429-455. https://doi.org/10.1177/0743558401165002

Bartkus, K. R., Nemelka, B., Nemelka, M., \& Gardner, P. (2012). Clarifying the meaning of extracurricular activity: a literature review of definitions. American Journal of Business Education, 5(6), 693-703. https://doi.org/10.19030/ajbe.v5i6.7391

Batool, Z. et al. (2012). National internship programmes and its evaluation: a case study of Punjab Region. Academic Research International, 2(2). 
Beheshtifar, M. et al. (2012). Destructive role of employee silence in organizational success. International Journal of Academic Research in Business and Social Sciences, 2(11), 275-282.

Broh, B. A. (2002). Linking extracurricular programming to academic achievement: who benefits and why? Sociology of Education, 75, 69-95. https://doi.org/10.2307/3090254

Burton, J. M., Horowitz, R., \& Abeles, H. (2000). Learning in and through arts: the question of transfer. Studies in Art Education, 41, 228-257. https://doi.org/10.2307/1320379

Carnegie Corporation of New York (1992). A Matter of Time: Risk and Opportunity in the non-school hours. New York: Author.

Chickering, A. (1969). Education and Identity. San Francisco, CA: Jossey-Bass.

Clements, W. H. (1974). The anatomy of a good student. Stevens Points, WI: Office of Institutional Research, University of Wisconsin-Stevens Point.

Darling, N., Caldwell, L. L., \& Smith, R. (2005). Participation in school-based extracurricular activities and adolescent adjustment. Journal of Leisure Research, 37(1), 51-76. https://doi.org/10.1080/00222216.2005.11950040

Darling, N., Hamilton, S. F., \& Shaver, K. H. (2003). Relationships outside the family: unrelated adults. In G.R. Adams \& M.D. Berzonsky (Eds), Blackwell Handbook of Adolescence, 349-370. Oxford, England: Blackwell Publishing.

Davalos, D. B., Chavez, E. L., \& Guardiola, R. J. (1999). The effects of extracurricular activity, ethnic identification, and perception of school on student dropout rates. Hispanic Journal of Behavior Sciences, 21(1), 61-77. https://doi.org/10.1177/0739986399211005

Deasy, R. J. (2003). Don't axe the arts. Principal, January/February, 14-15.

Denson, C. D., Stallworth, C. A., Hailey, C., \& Householder, D. L. (2015). Benefits of informal learning environments: a focused examination of STEM-based program environments. Journal of STEM Education, 16(1), 11-15.

Dumais, S. A. (2009). Cohort and gender differences in extracurricular participation: the relationship between activities, math achievement, and college expectations. Sociological Spectrum, 29, 72-100. https://doi.org/10.1080/02732170802480543

Durlak, J. A., Weissberg, R. P., Dymnicki, A. B., Taylor, R. D., \& Schellinger, K. B. (2011). The impact of enhancing students' social and emotional learning: a meta-analysis of school-based universal interventions. Child Development, Jan/Feb 2011, 82(1), 405-432. https://doi.org/10.1111/j.1467-8624.2010.01564.x

Eccles, J. S., \& Gootman, J. A. (2002). Community Programs to promote Youth Development. Washington, DC: National Academy Press.

Eccles, J. S., \& Barber, B. L. (1999). Student council, volunteering, basketball, or marching band: What kind of extracurricular involvement matters? Journal of Adolescent Research, 14(1), 10-43. https://doi.org/10.1177/0743558499141003

Eccles, J. S., Barber, B. L., Stone, M., \& Hunt, J. (2003). Extracurricular activities and adolescent development. Journal of Social Issues, 59(4), 865-889. https://doi.org/10.1046/j.0022-4537.2003.00095.x

Education Bureau. (2010). Reform Proposal for the Education System in Hong Kong. Hong Kong Special Administrative Region.

Education Bureau. (2012). Inspection Annual Report 2010/2011. Hong Kong Special Administrative Region (retrieved from www.edb.gov.hk).

Elder, G. H. Jr., \& Conger, R. D. (2000). Children of the land: Adversity and success in rural America. Chicago: The University of Chicago Press.

Farb, A. F., \& Matjasko, J. L. (2012). Recent advances in research on school-based extracurricular activities and adolescent development. Development Review, 32, 1-48. https://doi.org/10.1016/j.dr.2011.10.001

Gardner, M., Roth, J., \& Brooks-Gunn, J. (2008). Adolescents' participation in organized activities and developmental success 2 and 8 years after high school: Do sponsorship, duration and intensity matter? Developmental Psychology, 44, 814-830. https://doi.org/10.1037/0012-1649.44.3.814

George, P. (2002). Multicultural co-curricular activities help unify schools. The Education Digest, 68(1), 25-30. 
German, R. E. (1995). Co-curricular involvement characteristics of Bowling Green State University honors students. Reports - Research/Technical, 30 June 1995, Bowling Green State University, OH, USA.

Hawkins, A. L. (2010). Relationship between undergraduate student activity and academic performance. College of Technology Directed Projects, Purdue University.

Holland, A., \& Andre, T. (1987), Participation in extracurricular activities in secondary school: what is known, what needs to be known? Review of Educational Research, 57, 437-466. https://doi.org/10.3102/00346543057004437

Huang, Y. R., \& Chang, S. M. (2004). Academic and co-curricular involvement: their relationship and the best combinations for student growth. Journal of College Student Development, 45(4), 391-406. https://doi.org/10.1353/csd.2004.0049

Hunt, D. H. (2005). The effect of extracurricular activities in the educational process: influence on academic outcomes. Sociological Spectrum, 2, 417-445. https://doi.org/10.1080/027321790947171

Jordan, W. J., \& Nettles, S. M. (1999). How students invest their time outside of school: effects on school-related outcomes. Social Psychology of Education, 3(4), 217-243. https://doi.org/10.1023/A:1009655611694

Khmelkov, V. T., \& Hallinan, M. T. (1999), Organizational effects on race relations in schools. Journal of Social Issues, 55(4), 627-645. https://doi.org/10.1111/0022-4537.00139

Knefelkamp, L., Widick, C., \& Parker, C. (1978). New Directions for Student Services: Applying New Developmental Findings. San Francisco: Jossey-Bass.

Kreager, D. A. (2007). Unnecessary roughness? School sports, peer networks and male adolescent violence. American Sociological Review, 72, 705-724. https://doi.org/10.1177/000312240707200503

Laguador, J. M. (2013). Developing students' attitude leading towards a life-changing career. Educational Research International, 1(3), 28-33.

Landers, D., \& Landers, D. (1978). Socialization via interscholastic athletics, its effect on delinquency. Sociology of Education, 51, 299-301. https://doi.org/10.2307/2112368

Lanjewar, J. (2014). Importance of co-curriculum activities to students. Sai Om Journal of Commerce and Management, 1(11), 15-19.

Larson, R. W., \& Verma, S. (1999). How children and adolescents spend time across the world: work, play, and $\begin{array}{lllll}\text { developmental } & \text { opportunities. } & \text { Psychological } & \text { Bulletin, } & 125,\end{array}$ https://doi.org/10.1037/0033-2909.125.6.701

Larson, R. W., Hansen, D. M., \& Moneta, G. (2006). Differing profiles of development experiences across types of organized youth activities. Developmental Psychology, 42, 849-863. https://doi.org/10.1037/0012-1649.42.5.849

Lawhorn, B. (2009). Extra-curricular activities. Occupational Outlook Quarterly, Winter 2008-2009, 16-21.

Leung, C. H., Ng, C. W., \& Chan, P. O. (2011). Can co-curricular activities enhance the learning effectiveness of students: an application to the sub-degree students in Hong Kong. International Journal of Teaching \& Learning in Higher Education, 23(3), 329-341.

Light, R. (1990). The Harvard assessment seminars: explorations with students and faculty about teaching, learning and student life (First Report). Cambridge M.A.: Harvard University Graduate School of Education.

Mahoney, J. L., \& Stattin, H. (2000). Leisure activities and adolescent antisocial behavior: the role of structure and social context. Journal of Adolescence, 23, 113-127. https://doi.org/10.1006/jado.2000.0302

Marsh, H. W., \& Kleitman, S. (2002). Extra-curricular school activities: the good, the bad, and the non-linear. Harvard Educational Review, 72(4), 464-514. https://doi.org/10.17763/haer.72.4.051388703v7v7736

Mathiasen, R. E. (1985). Characteristics of the college honors student. Journal of College Student Personnel, 26 , 171-173.

Mawi, C. L., \& Maisnam, P. (2014). Attitude and perception of the students towards higher secondary education in Churachandpur District of Manipur. International Journal of Interdisciplinary and Multidisciplinary Studies, 2(1), 97-104.

McLaughlin, M. (1992). Employability Skills Profile: What are employers looking for? (Report 81-92-E). Ottawa, 
ON: Conference Board of Canada.

McNeal, R. B. Jr. (1995). Extra-curricular activities and high school dropouts. Sociology of Education, 68(1), 62-80. https://doi.org/10.2307/2112764

Newmann, F. M. (1998). How secondary schools contribute to academic success. In K. Borman, \& B. Schneider (Eds), The adolescent years: Social influences and educational challenges: Ninety-seventh yearbook of the National Society for the Study of Education, Part I, 88-108. Chicago, IL, USA: The National Society for the Study of Education.

Pittman, K., Tolman, J., \& Yohalem, N. (in press). Developing a comprehensive agenda for the out-of-school hours: lessons and challenges across cities. In J. L. Mahoney, J. S. Eccles, \& R. W. Larson (Eds), Organized activities as contexts of development: Extracurricular activities, after-school and community programs. Mahwah, NJ: Lawrence Erlbaum and Associates.

Ross, L. C. (2000). The $32^{\text {nd }}$ Phi Delta Kappa/Gallup poll concludes that extra-curricular activity must be equal in importance to academic subjects. Phi Delta Kappan, 82(2).

Ryan, R. M., \& Deci, E. L. (2000). Self-determination theory and the facilitation of intrinsic motivation, social $\begin{array}{llll}\text { development, and } \quad \text { well-being. American } & \text { Psychologist, }\end{array}$ https://doi.org/10.1037/0003-066X.55.1.68

Shernoff, D. J., \& Vandell, D. L. (2007). Engagement in after-school program activities: Quality of experience from the perspective of participants. J. Youth Adolescence, 36, 891-903. https://doi.org/10.1007/s10964-007-9183-5

Tamsen, C. V., \& Bissonnette, K. (2008). Encouraging participation in enriching educational experiences co-curricular activities and community service. Institutional Analysis and Student Affairs, University of Buffalo.

Tan, D., \& Pope, M. (2007). Participation in co-curricular activities: Non-traditional student perspectives. College \& University, 83(1), 2-9.

Wong, H., \& Wong, R. (2013). An Empirical Study - Adoption of International Financial Reporting Standards (IFRS) in Hong Kong Education. Journal of Management Research, 5(4), Oct 2013. https://doi.org/10.5296/jmr.v5i4.4256

Yin, D., \& Lei, S. A. (2007). Impacts of campus involvement on hospitality student achievement and satisfaction. Education, Winter 2007, 282-293.

Yusoff, Y. et al. (2012). Employability skills performance score for fresh engineering graduates in Malaysian Industry. Asian Social Science, 8(16), 140-145. https://doi.org/10.5539/ass.v8n16p140

\section{Copyrights}

Copyright for this article is retained by the author(s), with first publication rights granted to the journal.

This is an open-access article distributed under the terms and conditions of the Creative Commons Attribution license (http://creativecommons.org/licenses/by/4.0/). 